\title{
Liver-specific magnetic resonance contrast medium in the evaluation of chronic liver disease
}

\author{
Aplicações do contraste hepato-específico de ressonância magnética \\ nas hepatopatias crônicas
}

Marcio Augusto Correia Rodrigues dos Reis ${ }^{1}$, Ronaldo Hueb Baroni ${ }^{1}$

\begin{abstract}
The hepatobiliary-specific contrast medium (gadoxetic acid Primovist ${ }^{\circledR}$ ) is primarily used to improve detection and characterization of focal hepatic lesions, such as in chronic liver disease patients with suspected hepatocellular carcinoma. Since the contrast medium is selectively taken up by functioning hepatocytes in the late hepatobiliary phase, it helps to detect typical hepatocellular carcinoma, which show low signal intensity on this phase. This imaging feature also assists in differentiating regenerative/dysplastic nodules from early hepatocellular carcinomas (with over 90\% accuracy), as well as hypervascular hepatocellular carcinomas from arterial pseudo-enhancement foci. Future perspectives include its use in quantification of hepatic function and fibrosis.
\end{abstract}

Keywords: Liver neoplasms/diagnosis; Liver diseases/diagnosis; Carcinoma, hepatocellular/diagnosis; Contrast media/utilization; Magnetic resonance imaging/methods

\section{RESUMO}

0 contraste hepato-específico (ácido gadoxético - Primovist ${ }^{\circledR}$ ) tem como utilidade principal melhorar a detecção e a caracterização de lesões hepáticas focais, por exemplo, em hepatopatas crônicos com suspeita de hepatocarcinoma. Por apresentar captação seletiva por hepatócitos funcionantes na fase hepatobiliar tardia, auxilia na deteç̧ão de hepatocarcinomas típicos - a maioria dos quais apresentando hipossinal nessa fase. Essa característica de imagem também auxilia na diferenciação entre nódulos regenerativos/ displásicos e hepatocarcinomas precoces (com mais de $90 \%$ de acurácia), e entre hepatocarcinomas hipervascularizados e focos de pseudorrealce arterial. Perspectivas futuras promissoras incluem sua utilização na quantificação de função e de fibrose hepáticas.

Descritores: Neoplasias hepáticas/diagnóstico; Hepatopatias/diagnóstico; Carcinoma hepatocelular/diagnóstico; Meios de contraste/utilização; Imagem por ressonância magnética/métodos

\section{INTRODUCTION}

Magnetic resonance imaging (MRI) is a well-established test to assess focal liver lesions. However, up to $60 \%$ of malignant nodules may not be detected or characterized by MRI, mainly those smaller than $1.0 \mathrm{~cm}$ and in cirrhotic livers. ${ }^{(1,2)}$

Liver-specific contrast media were developed to increase sensitivity and specificity of MRI in assessing focal lesions, as well as to overcome some of the limitations observed with extracellular contrast media. Among the liver-specific contrast media currently available, only gadoxetic acid (Gd-EOB-dTPA, Primovist ${ }^{\circledR}$, Bayer Schering, Berlin, Germany) is approved for clinical use in Brazil.

\section{PHYSICAL CHEMICAL PROPERTIES AND BIOAVAILABILITY}

Gd-EOB-dTPA is a liver-specific, gadolinium-based paramagnetic contrast, with combined properties of hepatocyte perfusion and selectivity. It was primarily developed to increase detection and characterization of focal hepatic lesions. After intravenous administration, Gd-EOB-dTPA is quickly distributed in the vascular/ interstitial compartment, allowing for a dynamic, multiphase study (arterial, portal and equilibrium phases).

Approximately 50\% of the injected dose of Gd-EOBdTPA is selectively captured by functioning hepatocytes and later excreted through bile, enabling acquisition of a late hepatobiliary phase, approximately 10-20 minutes after its injection. In this stage, hepatocyte-free lesions (or lesions with dysfunctional hepatocytes) show low MRI signal intensity (dark images on a bright liver), with

\footnotetext{
${ }^{1}$ Hospital Israelita Albert Einstein, São Paulo, SP, Brazil.
}

Corresponding author: Marcio Augusto Correia Rodrigues dos Reis - Department of Imaging, Hospital Israelita Albert Einstein - Avenida Albert Einstein, 627/701, 4th floor, building B - Morumbi Zip code: 05651-900 - São Paulo, SP, Brazil - Phone: (55 11) 2151-1233 - E-mail: marciorreis1@gmail.com

Received on: May 5, 2014 - Accepted on: Feb 8, 2015

DOI: 10.1590/S1679-45082015RW3159 
liver/lesion enhancement, improving the diagnostic capability of the test.

Due to its hepatocyte specificity, the recommended dose of gadolinium is up to four times lower than that recommended for extracellular contrast media. ${ }^{(3-5)}$

The high contrast uptake is due to the lipophilic properties of Gd-EOB-dTPA, favoring its passive diffusion by molecular transporters OATP1, which are in the basolateral membrane of normal hepatocytes. ${ }^{(6,7)}$ After uptake by hepatocytes, Gd-EOB-dTPA is eliminated by biliary $(50 \%)$ and urinary tracts $(50 \%)$. At molecular level, biliary excretion is dependent upon the molecular transporter MPR2 that is present on the cell canalicular membrane. ${ }^{(6,7)}$

\section{CLINICAL USE IN CHRONIC LIVER DISEASE}

Hepatocellular carcinomas (HCC) can be diagnosed in a non-invasive manner, by means of imaging tests in patients at increased risk. These lesions typically present intense arterial enhancement, with washout in venous and equilibrium phases both in computerized tomography (CT) and MRI. ${ }^{(8,9)}$

The presence of fat or pseudocapsule (peripheral enhancement mimicking a real capsule) in late phases increases reliability of diagnosis. Complementary findings in MRI include high-signal intensity on T2 and restricted diffusion of water molecules.

Different patterns for $\mathrm{HCC}$ were described after injection of Gd-EOB-dTPA, depending on expression of the molecular transporter OATP1. Since most HCC do not present with functioning hepatocytes, approximately 80 to $90 \%$ show low signal intensity in hepatobiliary phase in relation to the surrounding hepatic parenchyma ${ }^{(10,11)}$ (Figure 1).

However, about 10 and $20 \%$ of moderately or welldifferentiated HCC present an increased expression of OATP1 transporter, leading to isointensity or

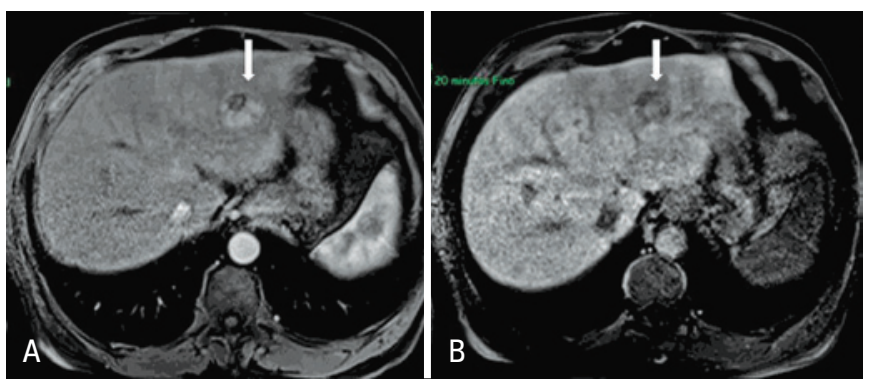

Figure 1. MRI with liver-specific contrast medium in a chronic liver disease patient showing a typical hepatocellular carcinoma on the left lobe. In the arterial phase $(A)$ the lesion is predominantly hypervascular, while in the late hepatobiliary phase it presents a (B) predominant low signal intensity hyperintensity in relation to the adjacent hepatic parenchyma. ${ }^{(10,11)}$

In approximately $10 \%$ of HCC cases, mainly in small lesions, low signal intensity in hepatobiliary phase may be observed with no hypervascular pattern in the arterial phase, or hyperintensity on T2 and diffusion-weighted images. ${ }^{(12)}$

\section{EARLY HEPATOCELLULAR CARCINOMA VERSUS REGENERATIVE/DYSPLASTIC NODULE}

The concept of early HCC described by the Liver Cancer Study Group of Japan and accepted worldwide, still leads to confusion between Japanese and Western pathologists. $^{(13-16)}$ Although several molecular markers were described for diagnosing early $\mathrm{HCC}$, with high diagnosis rate when used together, the accurate differentiation between dysplastic nodules and early HCC still requires identification of stromal invasion. Therefore, this differentiation is often impossible through biopsy, unless stromal invasion is included in the specimen. ${ }^{(17-19)}$

This differentiation in imaging tests used to be a challenge, even with advanced techniques, such as CT during liver arteriography or CT portography.

MRI with liver-specific contrast has become a true landmark in this field. Assuming that early HCC usually shows low signal intensity during the hepatobiliary phase, and that the dysplastic nodule shows iso/hypersignal (Figure 2), the diagnostic accuracy for early HCC today is over $95 \%$. (20-22) $^{2}$

Moreover, some studies that followed the natural course of hypovascular nodules presenting low signal intensity in the hepatobiliary phase showed that even if early HCC is ruled out in biopsy, it is very likely that this nodule will become hypervascular and develop into a typical HCC in the future. (23-25) $^{2}$

In other words, even if the biopsy rules out the diagnosis of early HCC, hypovascular nodules showing
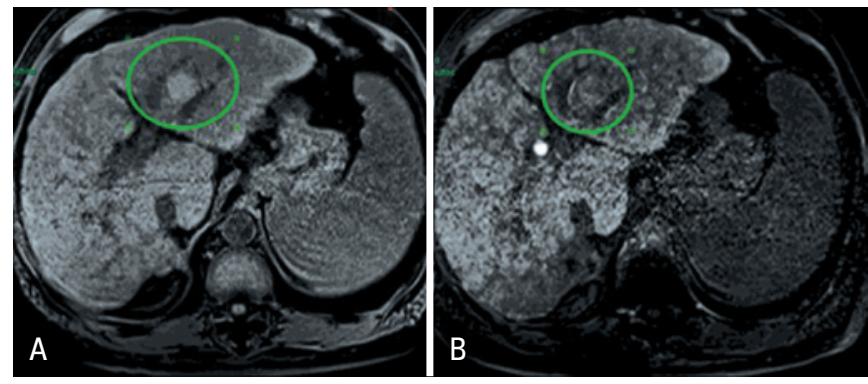

Figure 2. MRI with liver-specific contrast in a chronic liver disease patient showing lesion with characteristics of dysplastic nodule on the left lobe. Lesion shows hyperintensity in pre-contrast phase (A), and iso/hyperintensity in late hepatobiliary phase (B) 
low signal intensity in the hepatobiliary phase can be considered as such for therapy planning, because the risk of malignant changes is very high.

\section{HYPERVASCULAR HEPATOCELLULAR CARCINOMA VERSUS PSEUDOLESION WITH ARTERIAL ENHANCEMENT}

Arterioportal shunts can mimic hypervascular HCC in conventional MRI and CT studies. These shunts are observed more often in cirrhotic livers as hypervascular lesions ranging between 0.5 and $2.0 \mathrm{~cm}$ in size, usually without significant expression in any other sequence of the exam. ${ }^{(26,27)}$

However, up to approximately $50 \%$ of hypervascular foci in cirrhotic livers actually correspond to HCC and their characterization without repeated exams is a challenge. Today, this differentiation is possible with liver-specific contrast medium, because the shunts correspond to areas of preserved parenchyma (with isointensity to the remaining liver in the late hepatobiliary phase), while most HCC do not show functioning hepatocytes (with low signal intensity in late hepatobiliary phase) $)^{(27,28)}$ (Figure 3).

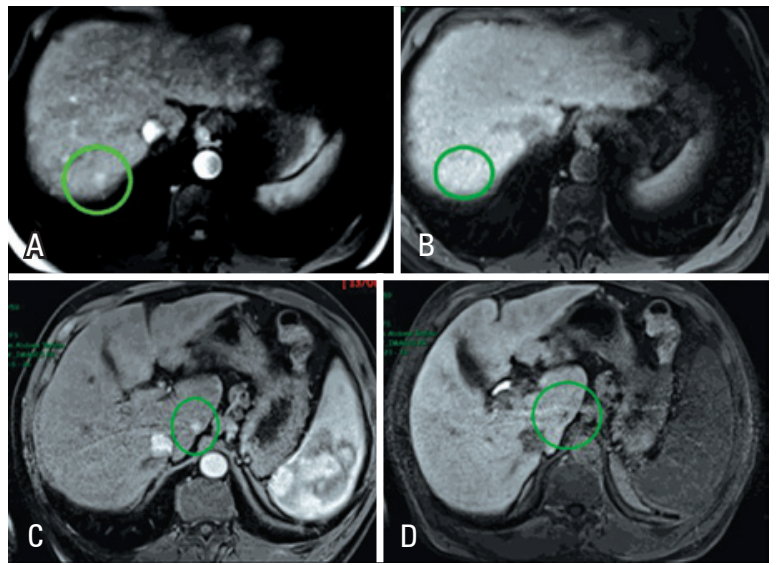

Figure 3. MRIs with liver-specific contrast medium of two chronic liver disease patients. The first patient shows nodular hypervascular focus on segment VII (A), with isointensity to the rest of the parenchyma in late hepatobiliary phase (B), indicating arterioportal shunt. The second patient shows a hypervascular nodular focus in the caudate lobe (C), with low signal intensity in late hepatobiliary phase (D), indicating a small hepatocellular carcinoma

\section{PERSPECTIVE}

Recent animal studies have suggested that MRI with liver-specific contrast medium might plays an important role in quantification of liver fibrosis. Tsuda et al. showed prolonged peak enhancement and slower washout of Gd-EOB-dTPA in rats with non-alcoholic steatohepatitis when compared to rats with simple steatosis. Moreover, a correlation between the level of fibrosis and the prolonged enhancement peak and washout period was demonstrated. ${ }^{(29,30)}$

Another use of Gd-EOB-dTPA still under investigation is the quantitative assessment of liver function. ${ }^{(31-37)}$ Its main advantages are the non-invasive assessment and the regional quantification of liver function, potentially useful to predict residual function in patients that will undergo partial hepatectomy. Gd-EOB-dTPA can also be used to diagnose early liver failure and other parenchymal manifestations of post-transplant complications. ${ }^{(38)}$

\section{CONCLUSION}

Gadoxetic acid as a liver-specific contrast medium has been increasingly used in chronic liver disease patients, mainly to assess hepatocellular carcinomas and to differentiate it from other focal lesions.

Future perspectives include its use in quantification of fibrosis and liver function.

\section{REFERENCES}

1 Chanyaputhipong J, Low SC, Chow PK. Gadoxetate Acid-Enhanced MR Imaging for HCC: A Review for Clinicians. Int J Hepatol. 2011;2011:489342.

2. Pauleit D, Textor J, Bachmann R, Conrad R, Flacke S, Layer G, et al. Hepatocellular carcinoma: detection with gadolinium- and ferumoxides-enhanced MR imaging of the liver. Radiology. 2002;222(1):73-80.

3. Weinmann HJ, Schuhmann-Giampieri G, Schmitt-Willich H, Vogler H, Frenzel T, Gries H. A new lipophilic gadolinium chelate as a tissue-specific contrast medium for MRI. Magn Reson Med. 1991;22(2):233-7; discussion 242.

4. Hamm B, Staks T, Mühler A, Bollow M, Taupitz M, Frenzel T, et al. Phase I clinical evaluation of Gd-EOB-DTPA as a hepatobiliary MR contrast agent: safety, pharmacokinetics, and MR imaging. Radiology. 1995;195(3):785-92.

5. Reimer P, Rummeny EJ, Shamsi K, Balzer T, Daldrup HE, Tombach B, et al Phase II clinical evaluation of Gd-EOB-DTPA: dose, safety aspects, and pulse sequence. Radiology. 1996;199(1):177-83.

6. van Montfoort JE, Stieger B, Meijer DK, Weinmann HJ, Meier PJ, Fattinger KE. Hepatic uptake of the magnetic resonance imaging contrast agent gadoxetate by the organic anion transporting polypeptide Oatp1. J Pharmacol Exp Ther. 1999;290(1):153-7.

7. Libra A, Fernetti C, Lorusso V, Visigalli M, Anelli PL, Staud F, et al. Molecular determinants in the transport of a bile acid-derived diagnostic agent in tumoral and nontumoral cell lines of human liver. J Pharmacol Exp Ther. 2006; 319(2):809-17.

8. Bartolozzi C, Battaglia V, Bozzi E. HCC diagnosis with liver-specific MRI--close to histopathology. Dig Dis. 2009;27(2):125-30. Review.

9. Ba-Ssalamah A, Uffmann M, Saini S, Bastati N, Herold C, Schima W. Clinica value of MRI liver-specific contrast agents: a tailored examination for a confident non-invasive diagnosis of focal liver lesions. Eur Radiol. 2009;19(2):342-57. Review.

10. Kim SH, Kim SH, Lee J, Kim MJ, Jeon YH, Park Y, et al. Gadoxetic acid-enhanced $\mathrm{MRI}$ versus triple-phase MDCT for the preoperative detection of hepatocellular carcinoma. AJR Am J Roentgenol. 2009;192(6):1675-81

11. Frericks BB, Loddenkemper C, Huppertz A, Valdeig S, Stroux A, Seja M, et al. Qualitative and quantitative evaluation of hepatocellular carcinoma and cirrhotic liver enhancement using Gd-EOB-DTPA. AJR Am J Roentgenol. 2009; 193(4):1053-60. 
12. Ahn SS, Kim MJ, Lim JS, Hong HS, Chung YE, Choi JY. Added value of gadoxetic acid-enhanced hepatobiliary phase MR imaging in the diagnosis of hepatocellular carcinoma. Radiology. 2010;255(2):459-66.

13. Kudo M. Early hepatocellular carcinoma: definition and diagnosis. Liver Cancer. 2013;2(2):69-72

14. The general rules for the clinical and pathological study of primary liver cancer. Liver Cancer Study Group of Japan. 3rd ed. Tokyo: Kanehara; 2010.

15. Theise ND, Park YN, Curado MP, Sakamoto M, Franceschi S, Torbenson M, et al. Hepatocellular carcinoma. In: Bosman FT, Carneiro F, Hruban RH, Theise ND, editors. WHO Classification of Tumours of the Digestive System. 4th ed. Lyon: International Agency for Research on Cancer; 2010. p 214-16.

16. Kojiro M. Diagnostic discrepancy of early hepatocellular carcinoma between Japan and West. Hepatol Res. 2007:37 Suppl 2:S121-4.

17. Chuma M, Sakamoto M, Yamazaki K, Ohta T, Ohki M, Asaka M, et al. Expression profiling in multistage hepatocarcinogenesis: identification of HSP70 as a molecular marker of early hepatocellular carcinoma. Hepatology. 2003;37(1):198-207.

18. Libbrecht L, Severi T, Cassiman D, Vander Borght S, Pirenne J, Nevens F, et al. Glypican-3 expression distinguishes small hepatocellular carcinomas from cirrhosis, dysplastic nodules, and focal nodular hyperplasia-like nodules. Am J Surg Pathol. 2006;30(11):1405-11.

19. Di Tommaso L, Franchi G, Park YN, Fiamengo B, Destro A, Morenghi E, et al. Diagnostic value of HSP70, glypican 3, and glutamine synthetase in hepatocellular nodules in cirrhosis. Hepatology. 2007:45(3):725-34.

20. Sano K, Ichikawa T, Motosugi U, Sou H, Muhi AM, Matsuda M, et al. Imaging study of early hepatocellular carcinoma: usefulness of gadoxetic acid-enhanced MR imaging. Radiology. 2011;261(3):834-44.

21. Kudo M. The 2008 Okuda lecture: Management of hepatocellular carcinoma: from surveillance to molecular targeted therapy. J Gastroenterol Hepatol. 2010;25(3):439-52.

22. Kitao A, Matsui O, Yoneda N, Kozaka K, Shinmura R, Koda W, et al. The uptake transporter OATP8 expression decreases during multistep hepatocarcinogenesis: correlation with gadoxetic acid enhanced MR imaging. Eur Radiol. 2011;21(10):2056-66.

23. Motosugi U, Ichikawa T, Sano K, Sou H, Onohara K, Muhi A, et al. Outcome of hypovascular hepatic nodules revealing no gadoxetic acid uptake in patients with chronic liver disease. J Magn Reson Imaging. 2011;34(1):88-94.

24. Kumada T, Toyoda H, Tada T, Sone Y, Fujimori M, Ogawa S, et al. Evolution of hypointense hepatocellular nodules observed only in the hepatobiliary phase of gadoxetate disodium-enhanced MRI. AJR Am J Roentgenol. 2011;197(1): 58-63.

25. Kobayashi S, Matsui O, Gabata T, Koda W, Minami T, Ryu Y, et al. Gadolinium ethoxybenzyl diethylenetriamine pentaacetic Acid-enhanced magnetic resonance imaging findings of borderline lesions at high risk for progression to hypervascular classic hepatocellular carcinoma. J Comput Assist Tomogr. 2011;35(2):181-6.
26. Ahn JH, Yu JS, Hwang SH, Chung JJ, Kim JH, Kim KW. Nontumorous arterioportal shunts in the liver: CT and MRI findings considering mechanisms and fate. Eur Radiol. 2010;20(2):385-94.

27. Motosugi U, Ichikawa T, Sou H, Sano K, Tominaga L, Muhi A, et al. Distinguishing hypervascular pseudolesions of the liver from hypervascular hepatocellular carcinomas with gadoxetic acid-enhanced MR imaging. Radiology. 2010;256(1):151-8

28. Sun HY, Lee JM, Shin Cl, Lee DH, Moon SK, Kim KW, et al. Gadoxetic acidenhanced magnetic resonance imaging for differentiating small hepatocellular carcinomas $(<$ or $=2 \mathrm{~cm}$ in diameter) from arterial enhancing pseudolesions: special emphasis on hepatobiliary phase imaging. Invest Radiol. 2010;45(2): 96-103.

29. Tsuda N, Okada M, Murakami T. Potential of gadolinium-ethoxybenzyldiethylenetriamine pentaacetic acid (Gd-EOB-DTPA) for differential diagnosis of nonalcoholic steatohepatitis and fatty liver in rats using magnetic resonance imaging. Invest Radiol. 2007;42(4):242-7.

30. Tsuda N, Okada M, Murakami T. New proposal for the staging of nonalcoholic steatohepatitis: evaluation of liver fibrosis on Gd-EOB-DTPA-enhanced MRI. Eur J Radiol. 2010;73(1):137-42.

31. Yamada A, Hara T, Li F, Fujinaga Y, Ueda K, Kadoya M, et al. Quantitative evaluation of liver function with use of gadoxetate disodium-enhanced MR imaging. Radiology. 2011;260(3):727-33.

32. Motosugi U, Ichikawa T, Sou H, Sano K, Tominaga L, Kitamura T, et al. Liver parenchymal enhancement of hepatocyte-phase images in Gd-EOB-DTPAenhanced MR imaging: which biological markers of the liver function affect the enhancement? J Magn Reson Imaging. 2009;30(5):1042-6.

33. Motosugi U, Ichikawa T, Oguri M, Sano K, Sou H, Muhi A, et al. Staging liver fibrosis by using liver-enhancement ratio of gadoxetic acid-enhanced MR imaging: comparison with aspartate aminotransferase-to-platelet ratio index. Magn Reson Imaging. 2011;29(8):1047-52.

34. Cho SH, Kang UR, Kim JD, Han YS, Choi DL. The value of gadoxetate disodiumenhanced MR imaging for predicting posthepatectomy liver failure after major hepatic resection: a preliminary study. Eur J Radiol. 2011;80(2):e195-200.

35. Watanabe H, Kanematsu M, Goshima S, Kondo H, Onozuka M, Moriyama N et al. Staging hepatic fibrosis: comparison of gadoxetate disodium-enhanced and diffusion-weighted MR imaging--preliminary observations. Radiology. 2011;259(1):142-50.

36. Katsube T, Okada M, Kumano S, Hori M, Imaoka I, Ishii K, et al. Estimation of liver function using T1 mapping on Gd-EOB-DTPA-enhanced magnetic resonance imaging. Invest Radiol. 2011;46(4):277-83. Erratum in: Invest Radiol. 2013; 48(2):112.

37. Kim T, Murakami T, Hasuike Y, Gotoh M, Kato N, Takahashi M, et al. Experimenta hepatic dysfunction: evaluation by MRI with Gd-EOB-DTPA. J Magn Reson Imaging. 1997;7(4):683-8.

38. Seale MK, Catalano OA, Saini S, Hahn PF, Sahani DV. Hepatobiliary-specific MR contrast agents: role in imaging the liver and biliary tree. Radiographics. 2009;29(6):1725-48. 